\title{
Proposal of a super trait for the optimum selection of popcorn progenies based on path analysis
}

\author{
A.T. do Amaral Júnior ${ }^{1}$, A. dos Santos ${ }^{1}$, I.F.S. Gerhardt ${ }^{1}$, R.N.F. Kurosawa ${ }^{1}$, \\ N.F. Moreira ${ }^{1}$, M.G. Pereira ${ }^{1}$, G. de A. Gravina ${ }^{2}$ and F.H. de L. Silva ${ }^{1}$ \\ ${ }^{1}$ Laboratório de Melhoramento Genético Vegetal, \\ Centro de Ciências e Tecnologias Agropecuárias, \\ Universidade Estadual do Norte Fluminense Darcy Ribeiro, \\ Campos dos Goytacazes, RJ, Brasil \\ ${ }^{2}$ Laboratório de Engenharia Agrícola do Centro de Ciência e Tecnologia \\ Agropecuária da Universidade Estadual do Norte Fluminense Darcy Ribeiro, \\ Campos dos Goytacazes, RJ, Brasil \\ Corresponding author: I.F.S. Gerhardt \\ E-mail: ismael-fernando@hotmail.com
}

Genet. Mol. Res. 15 (4): gmr15049309

Received September 20, 2016

Accepted October 24, 2016

Published December 19, 2016

DOI http://dx.doi.org/10.4238/gmr15049309

Copyright $(2016$ The Authors. This is an open-access article distributed under the terms of the Creative Commons Attribution ShareAlike (CC BY-SA) 4.0 License.

ABSTRACT. A challenge faced by popcorn breeding programs is the existence of a negative correlation between the two main traits, popping expansion and yield, which hinders simultaneous gains. The objective of this study was to investigate the use of a new variable or super trait, which favors the reliable selection of superior progenies. The super trait 'expanded popcorn volume per hectare' was introduced in the evaluation of 200 full-sib families of the eighth recurrent intrapopulation selection cycle, which were arranged in randomized blocks with three replicates in two environments. Although the inability 
to obtain simultaneous gains through selection via popping expansion or yield was confirmed, the super trait was positively associated with both yield and popping expansion, allowing simultaneous gains via indirect selection using 'expanded popcorn volume per hectare' as the main trait. This approach is recommended because this super trait can be used in breeding programs to optimize selective gains for the crop.

Key words: Popping expansion; Grain yield; Selection index; Zea mays

\section{INTRODUCTION}

Difficulties in the reliable definition of economically important traits in cultivated species have driven plant breeding researchers to focus on the concept of selection, as well as on information analysis and decision-making methods that result in simultaneous gains in quantitative and qualitative attributes (Bello et al., 2010).

For popcorn, the challenge of combining grain yield and popping expansion reflects a long-known problem involving the existence of a negative correlation between these two main traits (Willier and Brunson, 1927; Pacheco et al., 1998; Hallauer, 2001; Rangel et al., 2011; Cabral et al., 2016). This negative correlation indicates that direct selection using either of these traits results in a lower expression of the other trait in a reciprocal manner. Some specific attributes seem to favor one trait at the expense of the other.

Popping expansion benefits mainly from the chemical composition of the grains, such as the proportion of hard starch. In turn, factors that may benefit grain yield, such as the 100-grain weight, percentage of soft starch, and length and width of the grains, negatively contribute to popping expansion (Willier and Brunson, 1927; Hallauer et al., 2010). Additionally, grain yield is of special interest to producers, while consumers are mainly interested in the texture and softness of the popcorn; these are palatable attributes that are positively correlated with popping expansion (Sweley et al., 2012).

This leads to conflicts of interest between producers and consumers regarding a part of the popcorn production chain, and makes product quality subjective, depending on the primary attribute that is imposed. Furthermore, selecting superior progenies is not an easy task, because the traits of importance, which are mostly quantitative, are complex, especially because these interrelated traits are highly influenced by the environment.

The use of a unique trait that is positively and concomitantly associated with both grain yield and popcorn quality as a selection criterion would greatly increase the chances of success in a breeding program for superior genotypes. For this purpose, we propose using the variable 'expanded popcorn volume per hectare', expressed in $\mathrm{m}^{3} / \mathrm{ha}$, which refers to the multiplication of the mean grain yield of the plot (in $\mathrm{kg} / \mathrm{ha}$ ) by the popping expansion (in $\mathrm{mL} / \mathrm{g}$ ), thus, generating a super trait by aggregating the genotypes of high yield and popping expansion. The use of this variable thus circumvents the challenges associated with the use of multiple traits for the optimized selection of superior genotypes.

A correlation between traits allows selection based on only a single trait to result in simultaneous changes in one or more traits of agronomic importance. Therefore, many breeding programs make use of correlations when convenient. A correlation permits the evaluation of the degree of association between two traits and the viability of indirect selection, which in some cases, can lead to more rapid progress than direct selection. However, although correlations

Genetics and Molecular Research 15 (4): gmr15049309 
represent an easily obtained statistical parameter, care must be taken when interpreting their magnitude because the direction of the correlation, the difference in importance of the traits, the effect of two or more traits, and the environmental influence on trait expression makes this interpretation difficult (Falconer and Mackay, 1996).

The path analysis technique is of great importance for understanding the direct and indirect effects of variables that influence a basic or primary variable of greater interest (Cruz et al., 2012). This technique was introduced by Wright (1921) and is fundamental for clarifying possible misconceptions about correlations between two traits that may not necessarily have a cause-and-effect but may be influenced by a third trait imposed on both of the other traits.

The objective of the present study was to investigate the reliability of using the new variable 'expanded popcorn volume per hectare' as an option to mitigate the effects of the negative correlation between grain yield and popping expansion and to thereby facilitate the selection of superior progenies in popcorn breeding programs.

\section{MATERIAL AND METHODS}

The genetic material used in this study was that of the popcorn variety 'UNB-2U'. This variety originated from the population 'UNB-2' after two cycles of mass selection performed in Campos dos Goytacazes, Rio de Janeiro, RJ, Brazil; 'UNB-2' was previously obtained from the population 'UNB-1', which originated from an indigenous composite donated by the University of Brasilia (Universidade de Brasília - UNB). 'UNB-1' was crossed with the 'American' popcorn variety, and the plants selected from this cross were again crossed with another yellow-grain popcorn variety with a high yield and resistance to the pathogen Setosphaeria turcica. After the second cross, a mass selection was performed to generate a population with a high production capacity, resistance to $S$. turcica, and yellow grains. This selected population was backcrossed three times with the 'American' popcorn variety. The present-day population 'UNB-2U' has been improved via recurrent intrapopulation selection, leading to the accumulation of favorable alleles in the population in its seventh selection cycle (Pereira and Amaral Júnior, 2001; Freitas et al., 2014).

To obtain new full-sib families of the eighth recurrent intrapopulation selection cycle, 100 rows were sown with a mixture of seeds from the families selected in the previous cycle, and these were crossed and recombined in pairs. Rows of $5 \mathrm{~m}$ were used with $0.9-\mathrm{m}$ spacing between rows and $0.2-\mathrm{m}$ spacing between plants, resulting in 25 plants per row.

A total of 200 full-sib families were obtained and evaluated in a competition assay with six controls (four populations of previous cycles, the variety BRS Angela, and the hybrid IAC 125). The experiment was set up in October 2013 in two environments: one in the municipality of Campos dos Goytacazes, RJ ( $21^{\circ} 42^{\prime} 48^{\prime}$ 'S, $41^{\circ} 20^{\prime} 38^{\prime \prime} \mathrm{W}, 14 \mathrm{~m}$ in altitude), and the other at the Itaocara Experimental Station $\left(21^{\circ} 38^{\prime} 50^{\prime}\right.$ 'S, $42^{\circ} 03^{\prime} 46^{\prime \prime} \mathrm{W}, 58 \mathrm{~m}$ in altitude), which are located in the north and northwest Fluminense regions, respectively. The climate of both environments is classified as tropical according to the Köppen classification.

The experiment followed a randomized block design arranged in sets with replicates. Eight sets were used, and 31 treatments ( 25 full-sib families and six controls) were allocated within these sets, with three replicates. The experimental unit consisted of one row measuring $3.5 \mathrm{~m}$, with $0.9-\mathrm{m}$ spacing between rows and $0.2-\mathrm{m}$ spacing between plants, resulting in 16 plants per plot. Two seeds were sown per hole, and at 21 days after emergence, thinning was performed leaving only one plant per hole. Base fertilization consisted of $350 \mathrm{~kg} / \mathrm{ha}$ of the

Genetics and Molecular Research 15 (4): gmr15049309 
formula 4-14-8, and at 30 days, topdressing was performed with $60 \mathrm{~kg} / \mathrm{ha}$ nitrogen.

The variables evaluated were as follows: plant height $(\mathrm{PH})$, from the base of the stem to the insertion of the flag leaf, obtained by measuring six competitive plants per plot; ear height $(\mathrm{EH})$, from the base of the stem to the insertion of the first ear, obtained by measuring six competitive plants per plot; prolificacy (PRF), obtained by counting the number of ears per plant; weight of 100 grains (W100G), obtained by weighing 100 grains taken at random in three replicates per plot; grain yield (GY), obtained by weighing the grains after shucking each experimental unit and extrapolating to $\mathrm{kg} / \mathrm{ha}$; popping expansion (PE), obtained by determining the expanded popcorn volume, expressed in $\mathrm{mL} / \mathrm{g}$, in three replicates per plot; and 'expanded popcorn volume per hectare' (PV), obtained by multiplying the mean yield of the plot by the PE, generating the super trait of $\mathrm{PV}$, expressed in $\mathrm{m}^{3} /$ ha.

Analysis of variance was first performed separately for each environment, in order to verify the homogeneity of the residual variance. Subsequently, a joint analysis of variance was performed, considering the effects of progenies and environments as random, and the genotypic and phenotypic correlations were estimated.

The degree of multicollinearity of the matrix X'X was established based on its number of conditions (NC), which is the ratio between the largest and smallest eigenvalue of the correlation matrix X'X (Montgomery and Peck, 1981). This criterion considers that multicollinearity will be weak among the explanatory variables only when the ratio between the largest and smallest eigenvalue is equal to or less than 100. When the NC resulting from this division is $100<\mathrm{NC}<1000$, the multicollinearity is considered moderate-to-severe, and for $\mathrm{NC} \geq 1000$, the multicollinearity is considered severe.

Once the basic equations of the path analysis were established, the resolution in matrix form was obtained according to the equation: $X^{\prime} X \beta=X^{\prime} Y$, where $X^{\prime} X$ is a nonsingular matrix of the correlations between the primary variables, $\beta$ is the column vector of path coefficients, and $X^{\prime} Y$ is the column vector of the correlations between the explanatory variables and the dependent variable. The correlation between the dependent variable and the explanatory variables was estimated using Equation 1:

$$
r_{i x}=P_{i x}+\sum_{j^{1} i}^{n} r_{j} p_{j x}
$$

Where $r_{i x}$ is the correlation between the dependent variable and the i-th explanatory variable, $\mathrm{P}_{\mathrm{ix}}$ is the direct effect of variable $\mathrm{i}$ on the dependent variable, and $\mathrm{r}_{\mathrm{j}} \mathrm{P}_{\mathrm{jx}}$ is the indirect effect of variable $i$, via variable $j$, on the dependent variable. The least-square solution of this system is given by the equation: $\beta=\left(X^{\prime} X\right)^{-1}\left(X^{\prime} Y\right)$.

The following hypotheses were considered for the path analysis: i) the trait GY as the main variable and the others as explanatory variables; ii) the trait $\mathrm{PE}$ as the main variable and the others as explanatory variables; and iii) the trait PV as the main variable and the others as explanatory variables.

\section{RESULTS AND DISCUSSION}

The collinearity analysis resulted in an estimate of 33.27 , revealing weak collinearity among the traits evaluated, which allows the joint utilization of the variables analyzed. There was significance at $1 \%$ probability for estimates of the phenotypic and genotypic correlation

Genetics and Molecular Research 15 (4): gmr15049309 
coefficients for all variables analyzed, except for the correlation between PRF and PE (Table 1). The largest estimate of genotypic correlation was observed between the variables GY and PV, with a magnitude of 0.93. In general, the genotypic correlations were found to be higher than the phenotypic correlations, indicating that the linear association between these pairs of traits is more strongly influenced by genetic than environmental components.

Table 1. Estimates of the phenotypic $\left(r_{p}\right)$ and genotypic correlations $\left(r_{G}\right)$ among the seven agronomic traits evaluated in 200 full-sib families in the eighth recurrent selection cycle of the UENF-14 population. Campos dos Goytacazes, Rio de Janeiro, Brazil, 2014.

\begin{tabular}{|c|c|c|c|c|c|c|c|}
\hline & & $\mathrm{EH}$ & PRF & W100G & $\mathrm{PV}$ & GY & $\mathrm{PE}$ \\
\hline \multirow[t]{2}{*}{$\mathrm{PH}$} & $\mathrm{r}_{\mathrm{P}}$ & $0.82 * *$ & $0.48 * *$ & $0.67 * *$ & $0.69 * *$ & $0.75^{* *}$ & $0.11^{*}$ \\
\hline & $\mathrm{r}_{\mathrm{G}}$ & $0.85^{* *}$ & $0.59 * *$ & $0.77 * *$ & $0.75 * *$ & $0.81^{* *}$ & $0.15^{*}$ \\
\hline \multirow[t]{2}{*}{ EH } & $\mathrm{rP}$ & & $0.50 * *$ & $0.65^{* *}$ & $0.68 * *$ & $0.74 * *$ & $0.11 *$ \\
\hline & $\mathrm{r}_{\mathrm{G}}$ & & $0.56^{* *}$ & $0.71 * *$ & $0.74 * *$ & $0.79 * *$ & $0.15^{*}$ \\
\hline \multirow[t]{2}{*}{ PRF } & $\mathrm{rP}_{\mathrm{P}}$ & & & $0.35^{* *}$ & $0.57 * *$ & $0.62 * *$ & $0.05^{\text {ns }}$ \\
\hline & $\mathrm{r}_{\mathrm{G}}$ & & & $0.50 * *$ & $0.66 * *$ & $0.70^{* * *}$ & $0.11^{\mathrm{ns}}$ \\
\hline \multirow[t]{2}{*}{ W100G } & $\mathrm{r}_{\mathrm{P}}$ & & & & $0.65 * *$ & $0.68^{* * *}$ & $0.19^{*}$ \\
\hline & $\mathrm{r}_{\mathrm{G}}$ & & & & $0.69 * *$ & $0.74 * *$ & $0.18^{*}$ \\
\hline \multirow[t]{2}{*}{ PV } & $\mathrm{rp}_{\mathrm{P}}$ & & & & & $0.89 * *$ & $0.49 * *$ \\
\hline & $\mathrm{r}_{\mathrm{G}}$ & & & & & $0.93 * *$ & $0.51 * *$ \\
\hline \multirow[t]{2}{*}{ GY } & $\mathrm{rP}_{\mathrm{P}}$ & & & & & & $0.13^{*}$ \\
\hline & $\mathrm{r}_{\mathrm{G}}$ & & & & & & $0.21^{*}$ \\
\hline
\end{tabular}

PH: plant height; EH: ear height; PRF: prolificacy; W100G: weight of 100 grains; GY: grain yield; PE: popping expansion; PV: expanded popcorn volume per hectare; $* * *$, ns Significant at $\mathrm{P}<0.05, \mathrm{P}<0.01$, and not significant by the $\mathrm{F}$ test, respectively.

Despite the existence of a high positive correlation between GY and PV, the correlation between GY and PE was low (0.21), and in most cases, the correlation between these two traits was generally null or negative (Cabral et al., 2016). PE had a low correlation with most of the traits, which underlies the suggestion of using the super trait PV as a new variable to minimize this problem and optimize simultaneous gains regarding the main traits of economic importance. PV is derived from the product of $\mathrm{PE}$ and GY, and is denominated expanded popcorn volume per hectare.

In contrast to $\mathrm{PE}, \mathrm{GY}$ was estimated to have high positive correlations with the majority of variables, indicating that increases in $\mathrm{PH}, \mathrm{EH}, \mathrm{PRF}$, and $\mathrm{W} 100 \mathrm{G}$ can provide more productive popcorn genotypes. The positive correlation between $\mathrm{PH}$ and $\mathrm{EH}$ is common due to the association of the structural proportionality of the plant, as has been observed in common corn (Fancelli and Dourado Neto, 2000; Magalhães and Durães, 2002; Souza et al., 2008).

The coefficients of genotypic and phenotypic correlations quantify the associations in magnitude and direction, whereas these values are not sufficient to express the direct and indirect effects. However, path analysis enables a clearer interpretation of the direct influence of one variable on another, and the influence that other variables have on this association. Thus, it is possible to understand in detail the influences of the traits involved in a previously established diagram, and to explain the existence of positive and negative correlations, with either high or low magnitudes, between the traits studied (Santos et al., 2014).

Correlations among the variables PH, EH, PRF, and W100G with GY were all above 0.60; however, all of these variables had a small direct effect on GY. Therefore, intensified selection pressure on any of these variables may not provide satisfactory genetic gains in yield (Table 2). In this situation, indirect and significant causal traits must be considered simultaneously in the selection process.

Genetics and Molecular Research 15 (4): gmr15049309 
Table 2. Breakdown of the genotypic correlations into components of direct and indirect effect involving the main dependent variable, grain yield, and the independent explanatory variables evaluated in 200 full-sib families in the eighth recurrent selection cycle of the UENF-14 population. Campos dos Goytacazes, Rio de Janeiro, 2014.

\begin{tabular}{l|l|l|c}
\hline PH & Estimate & W100G & Estimate \\
\hline Direct effect on GY & 0.034 & Direct effect on GY & 0.051 \\
\hline Indirect effect via EH & 0.001 & Indirect effect via PH & 0.026 \\
\hline Indirect effect via PRF & 0.011 & Indirect effect via EH & 0.001 \\
\hline Indirect effect via W100G & 0.039 & Indirect effect via PRF & 0.009 \\
\hline Indirect effect via PV & 0.770 & Indirect effect via PV & 0.711 \\
\hline Indirect effect via PE & -0.049 & Indirect effect via PE & -0.060 \\
\hline Total & 0.809 & Total & 0.740 \\
\hline EH & & PV & 1.025 \\
\hline Direct effect on GY & 0.002 & Direct effect on GY & 0.001 \\
\hline Indirect effect via PH & 0.029 & Indirect effect via PH & 0.029 \\
\hline Indirect effect via PRF & 0.010 & Indirect effect via EH & 0.012 \\
\hline Indirect effect via W100G & 0.036 & Indirect effect via PRF & 0.036 \\
\hline Indirect effect via PV & 0.760 & Indirect effect via W100G & -0.171 \\
\hline Indirect effect via PE & -0.051 & Indirect effect via PE & 0.930 \\
\hline Total & 0.789 & Total & \\
\hline PRF & & PE & -0.334 \\
\hline Direct effect on GY & 0.018 & Direct effect on GY & 0.005 \\
\hline Indirect effect via PH & 0.020 & Indirect effect via PH & 0.001 \\
\hline Indirect effect via EH & 0.001 & Indirect effect via EH & 0.002 \\
\hline Indirect effect via W100G & 0.025 & Indirect effect via PRF & 0.009 \\
\hline Indirect effect via PV & 0.674 & Indirect effect via W100G & 0.526 \\
\hline Indirect effect via PE & -0.038 & Indirect effect via PV & 0.208 \\
\hline Total & 0.620 & Total & \\
\hline Coefficient of determination & 0.965 & & \\
\hline Residual effect & 0.184 & & \\
\hline PH: & & \\
\hline
\end{tabular}

PH: plant height; EH: ear height; PRF: prolificacy; W100G: weight of 100 grains; GY: grain yield; PE: popping expansion; PV: expanded popcorn volume per hectare.

Although the variables $\mathrm{PH}, \mathrm{EH}, \mathrm{PRF}$, and W100G were positively correlated with GY (Table 1), the direct effects were small (Table 2). In this case, selection based only on GY cannot provide satisfactory gains in the other traits, thus motivating the adoption of simultaneous selection based on traits that have considerable effects for indirect selection. This can be achieved using the variable PV, which appears to be a super trait since it was estimated to provide a large direct effect on GY, with a magnitude of 1.025 (Table 2). This estimate suggested an even greater effect, as it resulted from the breakdown of a high-correlation coefficient estimate (0.93), thus indicating the advantage of using PV in the optimization of simultaneous selection.

$\mathrm{PE}$ is the most important quality trait in popcorn, and the total estimated correlation with GY, although of a low magnitude, was positive (Table 2). A similar result was reported by Daros et al. (2004), who observed positive phenotypic and genotypic correlations between $\mathrm{PE}$ and GY in two cycles of recurrent selection. Those authors reported that there is a trend towards an increased genotypic correlation between GY and PE, resulting from the increased concentration of favorable alleles in successive recurrent selection cycles. However, in popcorn, the existence of a negative correlation between PE and GY is already known (Willier and Brunson, 1927; Hallauer, 2001; Rangel et al., 2011; Cabral et al., 2016), which hinders simultaneous gains in the main traits of importance to the crop, making it necessary to employ genetic-statistical procedures that minimize the deleterious effects of the correlated response.

When using PE as the primary variable, the explanatory variables $\mathrm{PH}, \mathrm{EH}, \mathrm{PRF}$, and

Genetics and Molecular Research 15 (4): gmr15049309 
W100G were found to exhibit small, and mostly negative, direct effects. The total correlations of these variables with PE were less than 0.2, indicating a low correlation between these variables and PE (Table 3 ). Low correlation coefficients do not imply that a relationship is lacking between two variables, but that a linear relationship between the variables is absent (Cruz et al., 2012). Considering the direct effect of these variables, the values were found to be lower than the residual effect (0.440). This implies that the increase in PE does not have a cause-and-effect relationship with these variables, confirming the low correlation coefficients found between them and PE (Table 3).

Table 3. Breakdown of the genotypic correlations into components of direct and indirect effect involving the main dependent variable, popping expansion, and the independent explanatory variables evaluated in 200 full-sib families in the eighth recurrent selection cycle of the UENF-14 population. Campos dos Goytacazes, Rio de Janeiro, 2014.

\begin{tabular}{l|l|l|c}
\hline PH & Estimate & W100G & Estimate \\
\hline Direct effect on PE & -0.030 & Direct effect on PE & 0.065 \\
\hline Indirect effect via EH & -0.071 & Indirect effect via PH & -0.023 \\
\hline Indirect effect via PRF & -0.045 & Indirect effect via EH & -0.059 \\
\hline Indirect effect via W100G & 0.050 & Indirect effect via PRF & -0.038 \\
\hline Indirect effect via PV & 1.783 & Indirect effect via PV & 1.646 \\
\hline Indirect effect via GY & -1.538 & Indirect effect via GY & -1.408 \\
\hline Total & 0.147 & Total & 0.181 \\
\hline EH & & PV & \\
\hline Direct effect on PE & -0.083 & Direct effect on PE & 2.372 \\
\hline Indirect effect via PH & -0.025 & Indirect effect via PH & -0.022 \\
\hline Indirect effect via PRF & -0.043 & Indirect effect via EH & -0.062 \\
\hline Indirect effect via W100G & 0.046 & Indirect effect via PRF & -0.051 \\
\hline Indirect effect via PV & 1.760 & Indirect effect via W100G & 0.045 \\
\hline Indirect effect via GY & -1.499 & Indirect effect via GY & -1.768 \\
\hline Total & 0.153 & Total & 0.513 \\
\hline PRF & & GY & \\
\hline Direct effect on PE & -0.078 & Direct effect on PE & -1.900 \\
\hline Indirect effect via PH & -0.017 & Indirect effect via PH & -0.024 \\
\hline Indirect effect via EH & -0.046 & Indirect effect via EH & -0.066 \\
\hline Indirect effect via W100G & 0.032 & Indirect effect via PRF & -0.054 \\
\hline Indirect effect via PV & 1.560 & Indirect effect via W100G & 0.048 \\
\hline Indirect effect via GY & -1.335 & Indirect effect via PV & 2.206 \\
\hline Total & 0.114 & Total & 0.208 \\
\hline Coefficient of determination & 0.805 & & \\
\hline Residual effect & 0.440 & & \\
\hline
\end{tabular}

PH: plant height; EH: ear height; PRF: prolificacy; W100G: weight of 100 grains; GY: grain yield; PE: popping expansion; PV: expanded popcorn volume per hectare.

For efficient indirect selection in breeding, it is important to identify those traits with the greatest direct positive effect among the traits with highly correlated with the base variable. In this sense, the super trait PV proposed in this analysis represents an option for indirect selection, because this variable had a large direct effect on PE.

The coefficient of determination was found to be 0.805 , indicating that $80.5 \%$ of PE is due to the effects of the variables analyzed, among which the largest contribution can be attributed to PV, for which the greatest direct and indirect effects were observed (Table 3).

When PV is considered as the main variable, and the other variables are considered as explanatory, a high total correlation was observed for the variables PH, EH, PRF, and W100G. However, as observed for GY and PE when used as the main variable, the direct effects were lower than the residual variable (Table 4). Therefore, it can be inferred that these variables are 
not the main determinants of changes in PE. In such a circumstance, it is necessary to apply strict selection criteria in order to eliminate undesirable indirect effects and to leverage the existing direct effect.

Table 4. Breakdown of the genotypic correlations into components of direct and indirect effect involving the main dependent variable, expanded popcorn volume per hectare, and the independent explanatory variables evaluated in 200 full-sib families in the eighth recurrent selection cycle of the UENF-14 population. Campos dos Goytacazes, Rio de Janeiro, 2014.

\begin{tabular}{l|c|l|c}
\hline PH & Estimate & W100G & Estimate \\
\hline Direct effect on PV & 0.003 & Direct effect on PV & -0.018 \\
\hline Indirect effect via EH & 0.030 & Indirect effect via PH & 0.002 \\
\hline Indirect effect via PRF & 0.016 & Indirect effect via EH & 0.025 \\
\hline Indirect effect via W100G & -0.014 & Indirect effect via PRF & 0.014 \\
\hline Indirect effect via PE & 0.049 & Indirect effect via PE & 0.060 \\
\hline Indirect effect via GY & 0.667 & Indirect effect via GY & 0.610 \\
\hline Total & 0.751 & Total & 0.694 \\
\hline EH & & PE & 0.335 \\
\hline Direct effect on PV & 0.035 & Direct effect on PV & 0.001 \\
\hline Indirect effect via PH & 0.002 & Indirect effect via PH & 0.004 \\
\hline Indirect effect via PRF & 0.015 & Indirect effect via EH & 0.003 \\
\hline Indirect effect via W100G & -0.013 & Indirect effect via PRF & -0.003 \\
\hline Indirect effect via PE & 0.051 & Indirect effect via W100G & 0.172 \\
\hline Indirect effect via GY & 0.650 & Indirect effect via GY & 0.513 \\
\hline Total & 0.742 & Total & \\
\hline PRF & & GY & 0.824 \\
\hline Direct effect on PV & 0.028 & Direct effect on PV & 0.002 \\
\hline Indirect effect via PH & 0.001 & Indirect effect via PH & 0.027 \\
\hline Indirect effect via EH & 0.019 & Indirect effect via EH & 0.019 \\
\hline Indirect effect via W100G & -0.009 & Indirect effect via PRF & -0.014 \\
\hline Indirect effect via PE & 0.038 & Indirect effect via W100G & 0.069 \\
\hline Indirect effect via GY & 0.579 & Indirect effect via PE & 0.930 \\
\hline Total & 0.657 & Total & \\
\hline Coefficient of determination & 0.972 & & \\
\hline Residual effect & 0.165 & & \\
\hline
\end{tabular}

PH: plant height; EH: ear height; PRF: prolificacy; W100G: weight of 100 grains; GY: grain yield; PE: popping expansion; PV: expanded popcorn volume per hectare.

PE and GY had large direct effects on PV and high total positive correlations, indicating the presence of a cause-and-effect relationship between these variables. In general, either with direct or indirect effects, the super trait PV provided the best estimates to explain GY and PE, indicating that selection for increased PV will result in simultaneous gains in GY and PE. This approach will facilitate the entire popcorn breeding process, because it is based on the selection of a single trait and can allow for dispensing with the use of selection indices.

The coefficient of determination was 0.972 , indicating that $97.2 \%$ of the popcorn volume was explained by the variables analyzed (Table 4) and that the independent variables, particularly PE and the GY, explained nearly all of the variation in the main trait PV.

There is a cause-and-effect relationship between PV and both GY and PE. The trait PV provides an advantageous option for the reliable acquisition of simultaneous gains in the major traits of economic interest in popcorn.

\section{Conflicts of interest}

The authors declare no conflict of interest.

Genetics and Molecular Research 15 (4): gmr15049309 


\section{ACKNOWLEDGMENTS}

We are grateful to Fundação de Amparo à Pesquisa do Estado do Rio de Janeiro (FAPERJ) and to Coordenação de Aperfeiçoamento de Pessoal de Nível Superior (CAPES) for scholarships granted and financial support.

\section{REFERENCES}

Bello OB, Abdulmaliq SY, Afolabi MS and Ige AS (2010). Correlation and path analysis of yield and agronomic characters among open pollinated maize varieties and their $\mathrm{F}_{1}$ hybrids in a diallel cross. Afr. J. Biotechnol. 9: 2633-2639.

Cabral PDS, Amaral Júnior AT, Freitas ILJ, Ribeiro RM, et al. (2016). Relação causa e efeito de caracteres quantitativos sobre a capacidade de expansão do grão em milho-pipoca. Rev. Cienc. Agron. 47: 108-117.

Cruz CD, Regazzi AJ and Carneiro PCS (2012). Modelos biométricos aplicados ao melhoramento genético. 4th edn. UFV, Viçosa.

Daros M, Amaral Júnior AT, Pereira MG, Santos FS, et al. (2004). Correlações entre caracteres agronômicos em dois ciclos de seleção recorrente em milho-pipoca. Cienc. Rural 34: 1389-1394. http://dx.doi.org/10.1590/S0103$\underline{84782004000500010}$

Falconer DS and Mackay TFC (1996). Introduction to quantitative genetics. 4th edn. Longman, Harlow.

Fancelli AL and Dourado Neto D (2000). Ecofisiologia e fenologia. In: Produção de milho (Fancelli AL, ed.). Agropecuária, Guaíba.

Freitas ILJ, do Amaral Júnior AT, Freitas SP, Jr., Cabral PDS, et al. (2014). Genetic gains in the UENF-14 popcorn population with recurrent selection. Genet. Mol. Res. 13: 518-527. http://dx.doi.org/10.4238/2014.January.21.21

Hallauer AR (2001). Specialty corns. 2nd edn. CRC Press, Boca Raton.

Hallauer AR, Carena MJ and Miranda Filho JB (2010). Quantitative genetics in maize breeding. Springer, New York.

Magalhães PC and Durães FOM (2002). Cultivo do milho: germinação e emergência. In: Comunicado Técnico 39 (Ministério da Agricultura, pecuária e abastecimento, eds.). EMBRAPA, Sete lagoas, 1-9. Available at [https://www. agencia.cnptia.embrapa.br/Repositorio/Comunicadotecnico39_000fi4t49ft02wyiv80mr28rz8dqcce6.pdf]. Accessed January 20, 2016.

Montgomery DC and Peck EA (1981). Introduction to linear regression analysis. John Wiley, New York.

Pacheco CAP, Gama EP, Guimarães PEO, Santos MX, et al. (1998). Estimativas de parâmetros genéticos nas populações CMS-42 e CMS-43 de milho de pipoca. Pesqui. Agropecu. Bras. 33: 1995-2001.

Pereira MG and Amaral Júnior AT (2001). Estimation of genetic components in popcorn based on the nested design. Crop Breed. Appl. Biotechnol. 1: 3-10. http://dx.doi.org/10.13082/1984-7033.v01n01a01

Rangel RM, Amaral Júnior AT, Gonçalves LSA, Freitas Júnior SP, et al. (2011). Análise biométrica de ganhos por seleção em população de milho-pipoca de quinto ciclo de seleção recorrente. Rev. Cienc. Agron. 42: 473-481. http://dx.doi. org/10.1590/S1806-66902011000200029

Santos A, Ceccon G, Davide LMC, Correa AM, et al. (2014). Correlations and path analysis of yield components in cowpea. Crop Breed. Appl. Biotechnol. 14: 82-87. http://dx.doi.org/10.1590/1984-70332014v14n2a15

Souza ARR, Miranda GV, Pereira MG and Ferreir PL (2008). Correlação de caracteres de uma população crioula de milho para sistema tradicional de cultivo. Rev. Caat. 21: 183-190.

Sweley JC, Rose DJ and Jackson DS (2012). Hybrid and environment effects on popcorn kernel physiochemical properties and their relationship to microwave popping performance. J. Cereal Sci. 55: 188-194. http://dx.doi.org/10.1016/j. jes.2011.11.006

Willier JG and Brunson AM (1927). Factors affecting the popping quality of pop Corn. J. Agric. Res. 35: 615-624.

Wright S (1921). Correlation and causation. J. Agric. Res. 20: 557-585.

Genetics and Molecular Research 15 (4): gmr15049309 